\title{
Apropriações da Psicologia Experimental por Dois Autores Jesuítas nas Primeiras Décadas do Século XX
}

Marina Massimi*

orcid.org/0000-0001-9103-9960

Universidade de São Paulo, Ribeirão Preto, SP, Brasil

\section{Resumo}

Esta pesquisa histórica analisa a modalidade de apropriação da psicologia experimental por dois autores da Companhia de Jesus - J. Fröbes e J. Lindworsky - nas primeiras décadas do século XX. Os dois pesquisadores escreveram várias obras sobre a ciência psicológica, seus objetos e métodos. Alguns desses textos são manuais didáticos, voltados para a difusão da área, inclusive no âmbito da Companhia. Através de uma análise dos referidos textos, observa-se uma evidente abertura para os novos métodos de conhecimento proporcionados pela ciência experimental; e, ao mesmo tempo, o esforço de preservar e assinalar a importância de conceitos derivados da psicologia filosófica tradicional. Desse modo, os dois autores jesuítas procuravam verificar a pertinência de aspetos das doutrinas tradicionais através dos novos métodos experimentais; bem como assinalar a relevância para a psicologia experimental, de processos psíquicos especialmente significativos do ponto de vista da antropologia jesuítica. Busca-se assim compatibilizar aspectos antigos e modernos, conforme uma modalidade de apropriação presente no universo intelectual da Companhia de Jesus, desde sua fundação.

Palavras-chaves: Josef Fröbes, Johannes Lindworsky, jesuítas e psicologia experimental.

\section{Appropriation of Experimental Psychology by Two Jesuit Authors in the First Decades of the Twentieth Century}

\begin{abstract}
This historical study analyzes the mode of appropriation of experimental psychology by two authors of the Society of Jesus - J. Fröbes and J. Lindworsky - in the first decades of the twentieth century. The two researchers wrote several works about psychological science, its objects and methods. Some of these texts are textbooks, aimed at the diffusion of the area, including in the context of the Society. Through an analysis of these texts, a clear opening for new methods of knowledge provided by experimental science can be seen, as well as effort to preserve and emphasize the importance of concepts from traditional philosophical psychology. Thus, the two Jesuit authors sought to verify the relevance of aspects of traditional doctrines through new experimental methods and to highlight the relevance to experimental psychology, psychic processes especially significant from the point of view of the Jesuit anthropology.
\end{abstract}

* Endereço para correspondência: Universidade de São Paulo, Departamento de Psicologia, Rua Américo Brasiliense, 1340/111, Ribeirão Preto, SP, Brasil 14050-010. Fone: 0163941-3668. E-mail: mmassimi3@ yahoo.com

Apoio financeiro: Conselho Nacional de Desenvolvimento Científico e Tecnológico (CNPq). 
They therefore sought to reconcile ancient and modern aspects, as a mode of appropriation present in the intellectual universe of the Society of Jesus since its founding.

Keywords: Josef Fröbes, Johannes Lindworsky, Jesuits and experimental psychology.

\section{Apropiación de la Psicología Experimental por Dos Autores Jesuitas en las Primeras Décadas del Siglo XX}

\section{Resumen}

Esta investigación histórica analiza el modo de apropiación de la psicología experimental por dos autores de la Compañía de Jesús - Fröbes J. y J. Lindworsky - en las primeras décadas del siglo XX. Los dos investigadores escribieron varias obras en la ciencia psicológica, sus objetos y métodos. Algunos de estos textos son libros de texto, destinado a la difusión de la psicologia experimental, también en la Compañia. A través de un análisis de estos textos, es evidente una clara apertura a nuevos métodos de conocimiento aportado por la ciencia experimental; y, al mismo tiempo, el esfuerzo para preservar y mostrar la importância de los conceptos de la psicología filosófica tradicional. De este modo, los dos autores jesuitas trataron de comprobar la relevancia de los aspectos de las doctrinas tradicionales a través de nuevos métodos experimentales; y señalar la relevancia de la psicología experimental para el estúdio de los procesos psíquicos especialmente significativos desde el punto de vista de la antropología jesuita. Buscando así hacer compatibles aspectos antiguos y modernos, de acuerdo com la forma de apropiación en el universo intelectual de la Compañía de Jesús desde su fundación.

Palabras clave: Josef Fröbes, Johannes Lindworsky, Jesuitas y la psicología experimental.

A categoria de apropriação proposta por $\mathrm{R}$. Chartier foca a reconstrução histórica "dos usos e das interpretações" de conceitos e teorias, na perspectiva de evidenciar "as condições e os processos que sustentam as operações de produção do sentido" realizadas na recepção dos textos transmissores dos referidos conceitos e teorias (1991, p. 180). Portanto, a ênfase é colocada na "pluralidade de empregos e compreensões" dos saberes, recebidos e transmitidos, e na "liberdade criadora - mesmo regulada - dos agentes" (1991, p. 180).

Neste texto nos ocupamos de agentes inseridos numa comunidade religiosa, a Companhia de Jesus, que desempenhou importante papel cultural no mundo moderno (Giard, 1995). O objetivo é evidenciar a modalidade de apropriação de teorias e práticas da psicologia experimental por parte desses agentes, num período histórico que veremos ser significativo para a história de sua comunidade de pertença: o fim do século XIX e as primeiras décadas do século XX. Realizaremos o objetivo proposto, analisando a contribuição de duas figuras muito significativas desse processo, na Europa: Josef Fröbes e Johannes Lindworsky.

\section{A Modalidade de Apropriação dos Saberes Própria da Companhia de Jesus}

A Companhia de Jesus, dissolvida no século XVIII, foi reconstituída em 1814, sendo que o século XIX foi dedicado à reconstrução da Companhia nos moldes de seu carisma originário, buscando, porém, adapta-lo às exigências do mundo contemporâneo (Colombo \& Massimi, 2014). Um dos aspetos deste esforço de adaptação é representado pela inserção dos jesuítas no ambiente intelectual, e especialmente, cientifico. Desde suas origens no século XVI, os jesuítas foram atuantes no mundo da ciência (Chinchilla \& Romano, 2008; Romano, 1999, 2012). De modo que, sobretudo a partir do fim do século XIX, vários dentre eles se interessaram e dedicaram às ciências e ao seu ensinamento nos institutos educacionais da Ordem. Por exemplo, o esforço de consolidação dessas instituições de 
ensino levou à criação da Universidade Gregoriana, em Roma, herdeira do Colégio Romano fundado por Inácio de Loyola em 1551, a qual iniciou a funcionar no ano de 1873 , chegando a uma organização completa como centro de ensino universitário, em 1930. A instituição fora planejada para ser o centro propulsor do pensamento jesuíta no século XX, no plano internacional, sendo frequentada por alunos (jesuítas e não jesuítas) do mundo inteiro (Gibert, 2006).

No domínio cientifico, um dos campos que despertou grande interesse dentre os jesuítas foi o das ciências da subjetividade: com efeito, a Companhia de Jesus, desde sua fundação, foi atenta a dimensão da experiência interior, inclusive na proposta de formação de seus membros, como é delineado pelos Exercícios espirituais de Inácio de Loyola (Massimi, 2016). Portanto, quando em meados do século XIX e nas primeiras décadas do século XX, assiste-se no mundo ocidental, ao crescimento da Psicologia, especialmente da Psicologia Experimental, no seio da reconstituída Companhia manifesta-se grande interesse por ela.

A tradição cultural da Companhia desde seus inícios buscou estabelecer nexos entre a tradição e o momento contemporâneo (Massimi, 2016). Esta posição cultural se inscreve na própria identidade social e religiosa dos jesuítas: a Companhia nascera no século XVI, no contexto histórico do Humanismo, especificamente na Universidade de Paris onde o fundador, Inácio de Loyola estudou e criou uma comunidade de estudantes e docentes, que se constituiu no seu primeiro núcleo. Paris, importante centro propulsor da filosofia escolástica, ou tomista, desde a Idade Média, no século XVI era imbuída também pelos ideais humanistas. Por isto, o estudo de Tomás à luz dos autores humanistas e renascentistas caracterizou desde então a formação jesuítica (Caeiro, 1982).

A compatibilização entre saberes da tradição e saberes da modernidade era feita seguindo o critério da acomodação, derivado da arte retórica romana e empregado no âmbito da Companhia, de modo amplo, visando propiciar o diálogo com o interlocutor e com o contexto, para a melhor realização dos objetivos missionários
(Massimi \& Freitas, 2007). No plano intelectual, isto implicava a apropriação da tradição filosófica do passado, à luz das influências e das mudanças culturais significativas do período contemporâneo. No século XVI, por exemplo, os autores dos manuais Conimbricenses elaborados pelos jesuítas visando o ensino no colégio de Coimbra, realizavam uma releitura de Aristóteles à luz de Tomás de Aquino, sendo, porém, receptivos a uma vasta gama de influências, algumas próprias da tradição filosófica anterior, outras características do contexto intelectual do Humanismo e da Renascença, influências estas de teor mais propriamente filosófico, mas também médico ou de outras áreas da "filosofia natural". (Massimi, 2016, p. 173)

\section{Joseph Fröbes e o Empenho em Vetera Cum Novis Coniungere}

No início do século XX, o impasse entre tradição e renovação evidencia-se na leitura dos textos elaborados por autores da Companhia que se dedicaram ao estudo da psicologia. Emblemático é o manuscrito do jesuíta alemão, P. Joseph Fröbes (1866-1947) Psychologia Sensitiva, escrito em Valkenburg em 1911, documento que se encontra no Arquivo Histórico da Companhia de Jesus (ARSI) em Roma (ARSI: OPP. NN. 1028),

Antes da redação desse trabalho, Fröbes dedicava-se à atividade didática, inicialmente no campo das ciências, pois lecionara matemática e física. E, entre 1902 e 1904, seguiu cursos em Psicologia nas Universidades de Gottingen e de Leipzig, aqui sob a direção de W. Wundt, aprendendo com ele métodos da Psicologia Experimental. (Frielingsdorf, 2001)

O manuscrito encontrado no Arquivo foi escrito em latim, conforme a tradição das instituições de ensino católicas da época, e apresentado junto ao Ignatius Kolleg de Valkenburg (Fröbes, 1911), instituição onde o autor realizara o curso filosófico entre 1895 e 1898 e onde posteriormente lecionara até 1936 . No prefácio, Fröbes coloca a existência de duas áreas da Psi- 
cologia: a Psicologia Especulativa, ou Escolástica, e a Psicologia Empírica, ou Experimental. Afirma que essas devem confrontar-se reciprocamente, assim como o fazem a filosofia natural e as ciências naturais. Todavia, Fröbes comenta que, dada a situação contemporânea de separação entre ciências empíricas e ciências especulativas, seria impossível abordar as duas áreas num único tratado. Portanto, no texto proposto, ele se dispõe a proporcionar uma clara visão das ciências empíricas para que seja possível resolver de modo correto algumas questões filosóficas. Com efeito, acredita que os progressos das ciências empíricas permitam solucionar não tanto questões acerca das verdades fundamentais (tais como: a espiritualidade da alma, a liberdade da vontade, etc.) que foram deduzidas pelos filósofos a partir de fatos já conhecidos, "quanto aspectos concernentes à vida sensitiva". De modo análogo, afirma, "as ciências naturais colaboraram para solucionar questões da filosofia natural" (Fröbes, 1911, p. 4). Declara, portanto, que ao abordar o tema da vida sensorial, seguirá "uma sana filosofia peripatética" (Fröbes, 1911), onde, assim como o fez Aristóteles, conhecimentos antigos e novos serão compendiados e discutidos, "de modo que a adesão às doutrinas tradicionais não seja sustentada pela ignorância dos resultados das ciências modernas" (Fröbes, 1911) e, por sua vez, "a adesão a estas ciências não se baseie na ignorância das verdades adquiridas pela tradição filosófica" (Fröbes, 1911). Fröbes cita quais exemplos positivos desse diálogo entre filosofia e ciência, os trabalhos de dois autores: o neotomista D. J. Mercier (18511926), autor de Psychologie (1920); e o jesuita Michael Maher (1860-1918), autor de Psychology empirical and rational (1890/1902).

No inicio do tratado, ao discutir o termo psique, Fröbes (1911) observa que este assume diferentes significados e que existem algumas interpretações reducionistas, como por exemplo a que elimina a alma sensitiva, ou a que coloca uma oposição entre o psiquico e o fisiológico, possivelmente se referindo à tradição de derivação cartesiana e de cunho espiritualista. Por vida psiquica, entende a vida que tem consciência de si mesma. O autor diferencia entre vida sensorial e vida intelectual: esta realiza operações tais quais o raciocinio, a escolha de bens imateriais, sendo própria do homem, e não dos outros seres animais.

A exposição da psicologia sensorial é dividida em duas partes: a Psicologia geral, ou animal, que aborda o estudo da vida sensorial animal; e a "psicologia especial da vida afetiva", que concerne fenomênos como as sensações, as operações dos sentidos internos (termo que, que segundo Massimi, 2012, refere-se na tradição aristotelico tomista, à memória, à imaginação, ao senso comum e à vis aestimativa), os processos cognitivos e afetivos, a motivação, a atividade e o hábito.

O texto é redigido em latim, que como vimos era o idioma utilizado na época nas instituições escolares da Igreja católica, mas o autor recorre curiosamente ao uso do idioma alemão para tratar de assuntos polêmicos, atuais e discordantes da referida tradição.

Nessas partes, Fröbes (1911) discute teorias da psicologia experimental e da ciência: as teses de Loeb sobre tropismo (Loeb, 1890); W. Wundt e seu tratado de Psicologia fisiológica (Wundt, 1874); as discussões ocorridas no quinto congresso internacional de Psicologia acontecido em Roma em 1905, com a presença de W. James (De Sanctis, 1906); as teorias de F. Galton $(1869,1883,1889)$ e de E. L. Thorndike (1904, $1905,1911)$.

Após a redação do manuscrito de 1911, entre 1915 e 1920 Fröbes publicou um tratado de Psicologia Experimental, redigido em língua alemã (Fröbes, 1917-1920), um compêndio de Psicologia especulativa escrito em latim para uso escolar (1927); e posteriormente um compêndio de Psicologia Experimental, também escrito em latim (Fröbes, 1915/1937). O compêndio foi traduzido em diferentes idiomas e usado para o ensino da disciplina em vários Países do mundo (Fröbes, 1961). A primeira edição do livro realizada por uma instituição oficial da Companhia, em língua latina, idioma oficial da Igreja católica, indica a plena aceitação da área no âmbito da Companhia de Jesus. 
No compendio, o autor distingue entre psicologia filosófica (especulativa, metafísica) e psicologia experimental, ou empírica. Escreve:

A psicologia, assim como a física e as demais ciências que saíram do seio da filosofia se separaram aos poucos em dois ramos científicos, que são a psicologia filosófica e a psicologia empírica. A psicologia filosófica (especulativa, metafísica) investiga, antes de tudo, as questões mais gerais que sempre foram de sumo interesse para toda a humanidade: estas questões são a substancialidade da alma, a relação entre o corpo e a alma, a controvérsia sobre o paralelismo psicofísico, a liberdade da vontade, a imortalidade da alma humana. E não se trata do fato que esta psicologia deduza a priori, a partir da essência da alma, suas propriedades, como alguns dos modernos afirmam; pelo contrário, se funda na observação dos atos e propriedades, para deduzir deles a natureza de seu substrato substancial. (Fröbes, 1961, p. 7)

Ao colocar esta distinção, Fröbes parece evocar a tradicional classificação da psicologia em racional e experimental proposta no âmbito da filosofia alemã no século XVIII. Essa classificação contemplava a organização da psicologia em duas áreas complementares: a psicologia empírica, ou cientifica, que aborda a vida psíquica em suas relações com a fisiologia e funda suas teorias em dados de experiência; e a psicologia racional, ou filosófica, que concerne questões tradicionais da psicologia filosófica (tais como origem e destino da alma, sua natureza, etc.), e usa os métodos dedutivos para elaborar suas conclusões. A formulação dessa distinção deve-se a C. Wolff (1679-1754); posteriormente, I. Kant (1724-1804) retomou-a, negando, porém, valor cientifico a ambas as áreas (Vidal, 2006). Ao longo do século XIX, vários enfoques de psicologia filosófica, como o espiritualista e o neotomista, assumiram essa divisão, que comparece também nos manuais escolásticos de filosofia. No Brasil, por exemplo, autores como Eduardo Ferreira França (1809-1857), em Investigações de Psicologia (1854). José Soriano de Souza (1933-1895) em Compêndio de Filo- sofia, ordenado segundo os principios e métodos do Doutor Angélico, S. Tomás de Aquino (1867) e Lições de filosofia elementar, racional e moral (1871) (Massimi, 1990, 2004, 2016), utilizam-se da referida classificação. No Congresso internacional de Roma que citamos anteriormente, o filósofo italiano F. De Sarlo apresentara uma preleção chamada La psicologia in rapporto alle scienze filosofiche expressando a necessidade de uma intima relação entre as duas disciplinas e evocava as duas formas de ser da psicologia: a filosófica e a experimental (De Sarlo 1905).

No ensino dos colégios da Companhia de Jesus, o debate acerca das relações entre psicologia racional e psicologia experimental, ou empírica, evidencia-se de modo contundente. Em documentos levantados junto ao Arquivo da Companhia de Jesus em Roma, referentes ao ensino filosófico na citada Universidade Gregoriana, verificamos a introdução do ensino da psicologia experimental juntamente à já tradicional psicologia racional, desde as primeiras décadas do século XX (MacSey, 1919; Monaco, 1919). Análoga inserção da psicologia nos currículos dos Colégios inacianos acontece em outros $\mathrm{Pa}$ íses: por exemplo, na Espanha (Guimerá, 1921). A modalidade de inserção da psicologia cientifica nos estudos jesuíticos, indicada pelos documentos, está em plena conformidade com aquele espírito de 'acomodação' ao ambiente cultural contemporâneo que, como vimos, caracteriza a Ordem de Loyola, desde suas origens. Assim como no século XVI os filósofos Conimbricenses procuravam compatibilizar em seus tratados as doutrinas dos 'antigos' com as dos 'modernos', na sequela dessa tradição, os pensadores jesuítas do século XX buscam dar continuidade a esse diálogo inerente ao carisma missionário dos inacianos, por exemplo, apontando para a complementaridade entre psicologia racional e psicologia experimental. Este processo de acomodação não ocorreu, porém, sem rupturas e intensos debates, conforme indica a leitura de outro documento referente à Província alemã da Companhia, elaborado por Ciran Grutt, o qual evidencia o dissenso existente entre os docentes de psicologia experimental e de psicologia ra- 
cional, nas instituições de ensino da Companhia naquela Província (Grutt, 1920).

Em suma, de modo geral, na época, manuais e tratados empregavam terminologias e modalidades de organização da área pautadas na existência dessas duas áreas complementares da psicologia, psicologia racional e psicologia empírica, ou experimental. Essas áreas eram, na maioria dos casos, incluídas no domínio da filosofia e de seu ensino.

Todavia, diferentemente da referida tradição que concebia a psicologia racional e a psicologia empírica como partes da filosofia, Fröbes, ao utilizar os termos "psicologia filosófica" e "psicologia experimental" assinala a diversidade de domínio de pertença de cada uma dessas áreas da psicologia: uma sendo parte da filosofia; e outra das ciências experimentais. Introduz assim uma relevante transformação epistemológica, numa perspectiva de (aparente) continuidade.

O objeto do Compêndio de Fröbes é a psicologia experimental, definida também como psicologia empírica:

A psicologia empírica (da mesma forma que a física experimental) toma por ponto de partida os fenômenos, e se propõe, antes de qualquer coisa, a descrevê-los, ordena-los e estabelecer leis especificas e gerais, conforme as normas da lógica indutiva; deixando, contudo, para a filosofia, o estudo das questões últimas acerca da atividade e da natureza da substancia. (1961, p. 8)

Fröbes define a psicologia experimental, a partir dos métodos que utiliza e reitera que esta é "a ciência que por meio da observação e do experimento, investiga os fenômenos psíquicos e suas leis". Atribui à psicologia experimental um domínio extenso que abrange todos "os fatos internos que cada um conhece apenas através da consciência, como pensamentos, reflexões, duvidas, recordações, sentimentos, afetos, desejos, decisões, e para dizê-lo numa palavra, os fatos psíquicos, os fenômenos psíquicos conscientes, ou da consciência" (1961, p. 8).

Fröbes coloca que a psicologia tem como objetivo a descrição e a explicação dos fenômenos e exemplifica a afirmação abordando o tema dos afetos e expressando total sintonia com a perspectiva wundtiana (Freitas, 2010). Escreve Fröbes: "descrever os afetos significa reduzir esses fenômenos pela análise em seus elementos simples, e ordenar os fatos elementares". A explicação implica "indicar as causas próximas de cada fato psíquico". Retoma também o tópico da sensação: explicar uma sensação é "evidenciar o estimulo fisico e sua ação no sistema nervoso central" (1961, p. 9). Aqui, sem cita-lo diretamente, Fröbes parece se inspirar no psicólogo inglês E. B. Titchener (1908). Para este autor, as sensações são "processos elementares conscientes, relacionados com processos corporais em órgãos definidos" (Titchener, 1899, p. 35), provocadas pela estimulação de órgãos periféricos e excitação do órgão central (Marcellos, 2012). Todavia Fröbes, para evitar acusações de reducionismo, observa que não se trata de reduzir as sensações às suas condições físicas, como se reduz o calor aos movimentos das moléculas; e sim discernir as causas dos fatos psíquicos, ou seja, reconhecer se essas se encontram no plano do domínio fisiológico, ou do domínio puramente psicológico.

A discussão acerca dos métodos da pesquisa psicológica é especialmente interessante: nela, evidencia-se o modo de apropriação realizado por Fröbes, caracterizado pela mediação entre os resultados da ciencia experimental e a tradição dos saberes da Companhia. Com efeito, Fröbes cita dentre os métodos da psicologia experimental, o método introspetivo, que define como autoobservação, e a observação do comportamento de outros. Ao abordar a introspeção, afirma que "a praticamos quando examinamos em nós mesmos os mótivos de uma decisão tomada, quando analisamos a nossa consciência" (Fröbes, 1961, p. 9). Vê-se, neste trecho, a tentativa de Fröbes de aproximar a introspeção, método próprio da psicologia experimental, e o exame de consciencia proposto pelos Exercícios espirituais de Inácio de Loyola, em particular no parágrafo quadragésimo terceiro do texto ("Modo de hacer el examen general...") (Loyola, 2002). Na perspectiva jesuítica, o exame de consciência é uma detalhada e cuidadosa análise das próprias vivencias interiores, que leva ao discernimento: processo pelo qual se distinguem os diversos ní- 
veis de determinada experiência com a finalidade de: esclarecer intenções, separar o que está misturado (e poderia confundir), avaliar os motivos de maneira correta, tendo em vista a tomada de decisões (Jurado, 1997). De modo particular, o "discernimento dos espíritos", é aplicado ao campo especifico de estados de ânimo, movimentos interiores, tendências e inclinações. $\mathrm{O}$ conhecimento de si e o adentrar em si mesmo são, na visão inaciana, o caminho fundamental para atingir a ordenação da vida anímica. Fröbes fornece um argumento para fundamentar a associação por ele proposta, entre introspecção wundtiana e exame de si inaciano: "a psicologia experimental contemporânea esforça-se por assimilar tudo o que nas antigas teorias tinha um valor real" (Fröbes, 1961, p. 15). Ao mesmo tempo, preocupa-se em esclarecer que a introdução do método experimental é um fator de inovação com relação ao passado, pois "torna possível que o trabalho de investigação seja similar aos procedimentos que, há tempo, são utilizados na física e na fisiologia, garantia de um progresso seguro e constante" (Fröbes, 1961, p. 15). A importância do método introspectivo na ciência da psique deve-se à característica peculiar dos fatos psíquicos, que, sendo fatos da consciência, "podem ser vistos unicamente pelo lado interno por aqueles que os experimentam" (Fröbes, 1961, p. 19). E aqui Fröbes coloca uma posição que se distancia bastante daquela dos fundadores da psicologia experimental, W. Wundt e W. James (Abib, 2009): a necessidade de considerar os fenômenos psíquicos como expressão do processo pessoal. Esta posição, por sua vez, sustenta a importância da psicologia filosófica, a qual se ocupa de investigar a natureza da pessoa. Desse modo, Fröbes afirma que

a característica do inteiro mundo psíquico é o caráter pessoal, ou seja, o fato dele ser sempre unido a um "eu". A unidade do eu não é uma união funcional como aquela existente entre as partes de um mecanismo, mas é um nexo que une todos os atos ao mesmo e idêntico eu. Os sentimentos, as imagens, e as sensações, são sentimentos "meus", imagens "minhas" e sensações "minhas". (Fröbes, 1961, p. 19)
Essa concepção evoca a doutrina acerca de pessoa exposta por Agostinho de Hipona na obra De Trinitate (Massimi, 2010). Segundo Agostinho, a alma sabe com certeza que existe, vive e entende. Este "saber" experiencial da alma acerca de si mesma não abarca apenas o campo do ser e do entender, mas também o da vontade e da memória. A existência de um núcleo unitário e único do ser humano, sujeito consciente de seus atos, é evidenciada então nestes termos: "me lembro de que tenho memória e inteligência e vontade, e entendo, quero e lembro; e quero querer e lembrar e entender; e lembro, ao mesmo tempo, toda minha memória e minha inteligência e minha vontade, toda inteira" (Agostinho, 416/1995, p. 331). Nesse ponto, Agostinho introduz o conceito de pessoa:

Eu recordo, eu entendo, eu amo, servindo-me destas três faculdades. Eu que não sou memória, nem inteligência, nem amor, mas que os possuo. Portanto, pode-se dizer que são de uma só pessoa, que ela possui as três faculdades, mas ela mesma não é essas três faculdades. (416/1995, p. 540)

Em suma, é evidente que Fröbes realiza uma apropriação da psicologia experimental buscando compatibiliza-la com a tradição dos conhecimentos filosóficos e teológicos acerca da pessoa e de seu psiquismo, através de uma operação de acomodação que focando os aspectos de proximide, coloca em segundo plano as diferenças inconciliaveis.

Ao reconstruir a história das fases do desenvolvimento da psicologia, o autor afirma com toda clareza a importância da introdução do método experimental em Psicologia, reconhecendo a G. Fechner o mérito deste passo:

A fundação da nova ciência deve-se a Fechner em sua famosa obra Elemente der Psychophysik (1860), onde reuniu uma multidão imensa de fatos antigos e novos da vida psíquica, estabeleceu os métodos psicológicos e realizou uma tentativa engenhosa de aplicar fórmulas matemáticas à grandeza da intensidade das sensações. $\mathrm{O}$ princípio da medida das sensações foi progressivamente abandonado, mas os métodos que ele proporcionou foram aperfeiçoados 
teórica e praticamente e são aplicados ainda hoje ao estudo de novas questões. (Fröbes, 1961, p. 15)

Curiosamente Fröbes, que como vimos fora aluno de Wundt, atribui a Fechner o papel de fundador da psicologia, através da "engenhosa tentativa" de aplicar a matematização para mensurar a intensidade das sensações. Ao mesmo tempo, Fröbes critica a psicologia associacionista, por limitar-se ao estudo das sensações "sem reconhecer a essência distinta dos pensamentos e da vontade" (Fröbes, 1961, p. 16): nesta frase, Fröbes usa um termo próprio da psicologia filosófica, "essência", para qualificar os fenomenos cognitivos e motivacionais que pertencem ao domínio da psicologia experimental. Além de W. James (Bertoni \& Pinto, 2007), vários filósofos contemporâneos de Fröbes assinalaram as falhas da psicologia associacionista, dentre eles, Edith Stein (1922/1992). Fröbes comenta que, devido à influência da psicologia associacionista na psicologia experimental, "as ciências do espírito não reconheceram nela um fundamento adequado e criaram uma psicologia espiritual" (1961, p. 16), através da contribuição de W. Dilthey e de E. Spranger. Com efeito, Wilhelm Dilthey (1833-1911) com sua obra Einleitung in die Geisteswissenschaften (1883/1948) buscou superar o referido monismo epistemológico propondo que, ao invés da simples adoção acrítica dos métodos das Ciências Naturais, se construísse uma metodologia adequada para a esfera do humano e de seus produtos, esfera que ele chamou de Ciências do Espírito (Geist), denotando pelo uso do termo, o aspecto qualitativo exclusivo da estrutura pessoal humana, não circunscrita apenas ao nível individual como também ao social.

E. Spranger (1882-1963), docente nas universidades de Leipzig, Tübingen e Berlim, dedicou-se, sobretudo, ao estudo da personalidade e da educação. Sua obra de 1914, Lebensformen: Geisteswissenschaftliche Psychologie und Ethik drr Personlichkeit, foi publicada em língua inglesa em 1928 (Spranger, 1928; Young, 1942), mas evidentemente Fröbes já tinha conhecimento de suas posições e pesquisas. Spranger, como
Dilthey, defendia a psicologia como ciência do espírito, cujo objeto devia ser o homem em suas relações com a cultura e a sociedade.

É interessante observar que Fröbes, apesar de reconhecer o aporte desses autores, não toma a dianteira na defesa da pertinência das ciências do espírito e sim propõe a ampliação do domínio da psicologia experimental. De fato, em seu texto observa que, após as críticas de Dilthey e Spranger, a psicologia experimental ampliou seu campo às regiões mais complexas da vida psíquica, de modo tal que "agora podemos encontrar na psicologia experimental estabelecida com base no método cientifico, o que anteriormente era tratado no âmbito da psicologia espiritual" (Fröbes, 1961, p. 17). Disso, depreende-se que "a psicologia experimental se constitui como o fundamento de todas as ciências do espírito" (Fröbes, 1961, p. 17). A defesa da importância e da proeminência da psicologia experimental se baseia no fato de que ela não sé limitou apenas ao estudo das sensações, mas "estendeu-se aos poucos às regiões mais elevadas da vida psíquica" (Fröbes, 1961, p. 17).

Essa posição é compartilhada por vários autores da época, sobretudo no contexto alemão, dentre eles o próprio Wundt (Araujo, 2016), mas é questionada por outros, sendo rotulada de psicologismo, na esteira da crítica realizada por Husserl (Porta, 2010). Stein também criticou o psicologismo em Psychische Kausalität. Beiträge zur philosophischen Begründung der Psychologie und der Geisteswissenschaften, Erste Abhandlung. Jahrbuch für Philosophie und phänomenologische Forschung (1922/1992), escrito produzido para conseguir a habilitação em filosofia em Gottingen em 1919.

A construção de argumentos realizada por Fröbes mostra que a apropriação da psicologia experimental nos moldes dos saberes da Companhia não é feita tanto entrando no mérito das questões epistemológicas, assim como Dilthey, Spranger, Husserl e Stein o fizeram, e sim atuando aquele processo de acomodação que acima descrevemos e que busca assinalar as similaridades entre conhecimento cientifico e conhecimento tradicional. Clara, de qualquer forma, é a 
opção de Fröbes pela supremacia cientifica (seja metodológica, seja de conteúdo) da psicologia experimental.

O Compêndio de Psicologia Experimental escrito por Fröbes teve várias edições a partir da primeira de 1915 (Fröbes, 1920, 1922, 1923, 1929, 1935, 1937, 1941). Dentre elas, uma, já citada, pela editora da Universidade Gregoriana, instituição da Companhia de Jesus, em 1937. Este fato evidencia que, no âmbito da Companhia, naquele momento, reconheceu-se definitivamente a importância da Psicologia Experimental.

A contribuição do jesuíta J. Fröbes na psicologia é assinalada por vários historiadores da psicologia (Misiak \& Staudt, 1954); sua autobiografia comparece no terceiro volume da obra monumental organizada por Murchison, $A$ History of Psychology in Autobiography (1936). Este fato confirma o papel de destaque desempenhado por Fröbes no âmbito da psicologia, papel amplamente reconhecido pela comunidade cientifica. No terceiro volume de Murchison, Fröbes é colocado no grupo dos mais importantes psicólogos alemães; e dos americanos James Rowland Angell, Madison Bentley, Harvey A. Carr, Edward Wheeler Scripture, Edward Lee Thorndike, John Broadus Watson.

$\mathrm{Na}$ autobiografia, Fröbes estrutura sua vida intelectual em três grandes blocos: sua experiência de vida como preparo para o trabalho cientifico; seu desempenho como psicólogo experimental; seu trabalho na área da psicologia filosófica. Relata sua formação no colégio jesuíta de Feldkirch na Áustria e afirma que aquele período foi o melhor da vida, por ter experimentado o fato de "a vivência religiosa permear sua vida inteira", dando-lhe motivação e entusiasmo (Murchison, 1936, p. 122). Essa experiência, juntamente com a admiração pelos docentes do colégio e o desejo de imita-los, levou-o à vocação sacerdotal na Companhia de Jesus; e afirma que, ao longo de cinquenta anos de vida nesta condição, nunca se arrependeu por essa decisão. Bastante pormenorizado é o relato da formação humanística recebida no noviciado e especificamente dos estudos filosóficos marcados pela filosofia escolástica. A propensão pelos estudos da física e da matemática, estimulada por alguns docentes brilhantes, incentivou-o a seguir o caminho das ciências. Narra que, após terminar a formação, já professor, leu casualmente um livro de psicologia experimental de W. Wundt, reconhecendo-o como o melhor caminho para cultivar sua aptidão para as ciências e ao mesmo tempo lidar com a experiência humana. Então, solicitou aos superiores a permissão de suspender por dois anos a atividade docente para realizar pesquisas em algum laboratório de psicologia experimental. Com este objetivo, foi para a Universidade de Gottingen entre 1902 e 1904, onde desenvolveu atividades experimentais no âmbito da psicofísica, sob a orientação de George Elias Müller. Nessa universidade, também frequentou aulas de psiquiatria e alguns cursos com E. Husserl. No último período de sua licença, passou para Leipzig, considerado o "berço da nova psicologia" (p. 129), tendo aulas com Wundt $\mathrm{e}$ frequentando seu laboratório. Nos dois anos que se seguiram, uma vez retornado às atividades didáticas, tentou integrar seus estudos no sentido de construir um panorama de todos os campos da psicologia, tanto experimental, quanto filosófica. Relata que, com esse objetivo, empreendeu a tarefa de redigir dois manuais, um de psicologia experimental (a primeira edição em 1905; e a segunda entre 1908 e 1910, bem mais extensa); e outro de psicologia filosófica, em 1920. Acerca de tais tratados, traduzidos também nas línguas inglesa e espanhola, apresentados anteriormente, Fröbes comenta que buscavam esclarecer a diferença de domínios e métodos, entre as duas áreas: a psicologia experimental realiza estudos empíricos e experimentais em termos da ciência positiva, omitindo quaisquer raciocínios filosóficos; sendo que as questões metafísicas não se constituem em premissas para a psicologia cientifica. A psicologia filosófica não é antitética a psicologia experimental e o objetivo de Fröbes é "compatibilizar antiga e nova psicologia" (Murchison, 1936, p. 143), tendo em vista também as contribuições importantes dessa área para a pedagogia. Sua narrativa autobiográfica termina com a declaração do propósito de construir uma adequada fundamentação filosófica da psicologia cientifica, em continuidade com a tradição 
escolástica. Apesar de não ter conseguido realizar o objetivo visado, a relevância de Fröbes, conforme afirmam Misiak e Staudt (1954), consistiu em assumir, na Alemanha, assim como D. Mercier na Bélgica, o papel de, no meio católico, integrar a psicologia filosófica com a psicologia experimental (vetera cum novis coniungere). Os dois historiadores destacam a importante função desempenhada pelo Compêndio de psicologia experimental, por ter defendido a aceitação universal dessa área como ciência separada e independente, encorajando os católicos ao estudo dela.

Os tratados e a atividade docente de Fröbes inspiraram aos jovens o entusiasmo pela área: um dos seus estudantes, Johannes Lindworsky, o seguiu neste caminho tornando-se por sua vez devotado à integração entre psicologia experimental e filosofia.

\section{Johannes Lindworsky e o Estudo Experimental da Vontade}

Johannes Lindworsky (1875-1939) possuía uma rica e diversificada formação cientifica e filosófica: doutorou-se em Munich sob a orientação de J. Fröbes, foi professor em Praga em 1928 e depois em Roma, na Universidade Gregoriana. Era simpatizante da escola de Würzburg e das pesquisas lá desenvolvidas que vertiam sobre o pensamento sem imagens; mas estudou, sobretudo, o conceito de vontade e motivação. Rozestraten (2004) coloca que, docente em Colônia, deu continuidade aos trabalhos de Kulpe e da escola de Würzburg. Escreveu vários tratados na área de psicologia que foram editados em vários idiomas e tiveram ampla difusão (OCLC Online Computer Library Center, 2010). Dentre eles, encontram-se: Der Wille (1919) e Willenshulke (1922), onde o autor usa dados experimentais de laboratório para refutar a doutrina tradicional da vontade como força e propor uma nova teoria fundada no conceito de motivação. Der Wille teve 33 edições publicadas em Alemanha entre 1921 e 1923; e 19 edições em outras línguas entre 1923 e 1986 . Willenshulke teve 26 edições em Alemanha entre 1922 e 1953; e 18 edições em outros idiomas entre 1926 e 1961. Lindwor- sky publicou também Psychologie der Aszese: Winke für eine psychologisch richtige Aszese (1935/1946), traduzido imediatamente em vários idiomas tendo dezoito edições publicadas entre 1935 e 1948; Experimental Psychology (1921/1939); e Theoretical Psychology (1932). O tratado de psicologia experimental teve 112 edições publicadas em várias línguas entre 1921 e 2016; o de psicologia teorética teve 23 edições entre 1932 e 2011. Em suma, os textos de Lindworsky desempenharam papel de relevo quanto à transmissão dos conhecimentos psicológicos, no mundo.

De modo semelhante a J. Fröbes, a produção de Lindworsky parece exemplificar a disposição à acomodação e a modalidade de apropriação dos saberes própria do espírito da Companhia: num texto de cunho religioso, dedicado à psicologia da ascese, ele afirma que a espiritualidade pode ser auxiliada pelos resultados e orientações decorrentes de avanços da psicologia cientifica. Assim, o recurso à ciência da psique pode auxiliar para que a formação espiritual possa formar homens autênticos e integrais (Lindworsky, 1935/1946).

Quando docente de filosofia em Praga, publica Experimentelle Psychologie (1921/1939) manual traduzido em várias línguas. Neste texto, Lindworsky afirma que "os métodos da psicologia experimental dividem-se conforme seus objetos e, sendo a consciência fonte primaria, a introspeção é o método privilegiado" (1921/1939, p. 10). A propósito da introspecção, Lindworsky evidencia que "o método cientifico privilegiado da ciencia experimental é a introspecção retrospectiva; mas, no entanto, esta, por si mesma, não consegue propocionar a construção de uma nova ciencia, devendo, portanto, ser unida à introspecção sistemática e experimental". E ainda define a essência do experimento, como "o introduzir voluntariamente na consciencia um determinado processo, visando a observação cientifica" (p. 11). Desse modo, esse autor, assim como Fröbes, ao associar a prática introspectiva, que como vimos era difundida na Companhia a partir dos Exercícios espirituais de Inácio de Loyola, à introspecção experimental de matriz wundtiana, realiza uma 
operação de acomodação entre duas tradições entre si muito distantes e uma apropriação da psicologia experimental nos moldes da visão jesuitica.

Nas já citadas obras sobre a vontade, Der Wille (1919) e Willenschule (1922), Lindworsky usa dados experimentais para estabelecer a primazia da motivação como chave da vontade. Para esses estudos, utilizara um método de introspecção sistemática, já discutido na oitava secção do primeiro tomo do tratado de Psicologia experimental: partindo dos estudos de $\mathrm{A}$. Michotte (1962), descreve a experiência da volição como ato no presente, em primeira pessoa, tendo sempre alguma finalidade e manifestando intensidades diferentes. Os resultados das pesquisas de Lindworsky demonstram que a capacidade de querer pode ser diferente entre os individuos: alguns têm mais força de vontade; outros, menos. Todavia, se considerarmos a força de vontade como a energia de um conteudo de consciência, de um conjunto de valores e fins, isto implica haver conjuntos de valores (motivos) que podem mobilizar totalmente a vontade, e outros que conseguem parcialmente. A conclusão de Lindworsky é que educar a vontade significa propor finalidades abrangentes e totalizantes que possam captar a energia dos jovens em todas as esferas da vida. O foco no tema da vontade é caro à Companhia de Jesus: dentre as produções mais importantes neste tema, lembramos o De arte voluntatis, libri sex: in quibus Platonicae, Stoicae, \& Christianae disciplinae medulla digeritur, succo omni politioris Philosophiae expresso ex Platone, Seneca, Epicteto, Dione Chrysostomo, Plotino, Iamblicho, \& alÿs: quorum sensa subtiliora artificiosiùs ordinantur; nonnulla emendantur, plurima adauntur nove, $\&$ argute (doravante DAV), escrito em 1631 pelo jesuíta J. E Nieremberg, dedicado à educação da vontade e baseado na concepção de que a vontade depende dos objetos da cognição (Pacheco, 2014a, 2014b). Desse modo, a concepção da vontade que inspira os estudos experimentais de Lindworsky é conforme a tradição jesuítica de matriz aristotélico-tomista que estabelece um vínculo profundo entre este processo psíquico e a cognição. Valores e fins, com efeitos, são obje- tos da cognição. Novamente, estamos diante de uma modalidade de apropriação que busca compatibilizar tradição e modernidade: a verificação de uma teoria de matriz tradicional, através de métodos experimentais.

Os escritos de Lindworsky tiveram grande difusão na Europa e nas Américas, sobretudo na área educacional. Sua tentativa de integração entre psicologia filosófica e experimental não se deu numa perspectiva epistemológica e sim pelo fato dele utilizar dados experimentais para construir teorias acerca dos fenômenos psicológicos. De modo que, nas pesquisas sobre vontade, por exemplo, integra experimentação e concepção filosófica; tendo o cuidado de afirmar que os estudos experimentais não conseguem comprovar diretamente a existência da liberdade, mas que podem evidenciar seus efeitos. Brennan (1969) ressalta também a importância de Lindworsky explicar a atenção como resultado da atividade conjunta de vontade e processos cognoscitivos.

\section{Conclusão}

As contribuições à psicologia nas primeiras décadas do século XX dos autores jesuítas que aqui analisamos evidenciam a importância que a psicologia cientifica assume no pensamento e na atuação da Companhia de Jesus e a peculiar modalidade de apropriação da mesma, compatibilizando a tradição cultural herdada com as novidades da ciência contemporânea. Desse modo, a psicologia filosófica de matriz tomista interpretada conforme a orientação filosófica geral do pensamento católico da época é apresentada em sua complementaridade com a psicologia experimental recém-criada. A visão de homem e dos processos anímicos alicerçada na tradição é verificada e discutida a partir dos métodos e das temáticas da ciência do mundo contemporâneo. Nesse sentido, a contraposição entre psicologia racional e psicologia experimental, oriunda da filosofia alemã, é reinterpretada no contexto jesuítico em termos de complementaridade, possibilitando aquele diálogo entre antigos e modernos que como vimos é preconizado pelo carisma da Companhia desde suas origens. 
Cabe ainda ressaltar que, se os jesuítas aderiram ao uso dos métodos experimentais em psicologia, contudo mantiveram a preferência para o estudo de temas especialmente significativos na tradição da Companhia, como o da vontade.

Num contexto histórico marcado pela ruptura entre saberes psicológicos próprios da tradição e novos conhecimentos fruto dos avanços científicos, Fröbes e Lindworsky protagonizaram a busca de uma continuidade alcançada de forma dinâmica, evidenciando possibilidades de interpretar, à luz da tradição, os resultados obtidos pela experimentação; e introduzindo usos novos da psicologia e seus recursos, voltados para a intervenção (por exemplo, no campo educacional) e a experimentação. Por exemplo, o método da introspecção experimental, apropriado pelos dois autores jesuítas de modo a aproxima-lo à prática do exame de si e do discernimento, é utilizado e difundido por eles através de suas aulas e, sobretudo, de seus tratados. Ao mesmo tempo, os dois autores defendem que os resultados da experimentação sejam aplicados em áreas tradicionalmente reservadas aos domínios da espiritualidade e da filosofia. Realmente, o já citado lema vetera cum novis coniungere sintetiza o modo de apropriação peculiar desses autores, moldado pelo seu pertencimento a tradição intelectual da Companhia de Jesus; mas também pela sua inserção dentro do universo cultural e cientifico de sua época, a partir do qual parecem buscar reinterpretar, em modo novo, conceitos e métodos da referida tradição.

\section{Referências}

Abib, J. A. D. (2009). Epistemologia pluralizada e história da psicologia. Scientiae Studia, 7(2), 195-208.

Agostinho. (1995). Sobre a Trindade (A. Belmonte, Trad.). São Paulo, SP: Paulus. (Original de 416).

Araujo, S. F. (2016). Wundt and the Philosophical Foundations of Psychology: A Reappraisal. New York: Springer.

Bertoni, P. G., \& Pinto, D. C. M. (2007). Mudança e continuidade: A formação Jamesiana do pensamento como um fluxo. Psicologia: Reflexão e Crítica, 20(2), 205-211.
Brennan, R. E. (1969). Psicología general (A. L. Maza, Trad., 2. ed.). Madrid: Morata.

Caeiro, F. G. (1982). O pensamento filosófico do século XVI ao século XVIII. In Portugal e no Brasil, Acta do l Congresso Luso-Brasileiro de Filosofia (pp. 51-90). Braga, Portugal: Universidade Católica.

Chartier, R. (1991). O mundo como representação. Estudos Avançados, 11(5), 173-189.

Chinchilla, P., \& Romano, A. (Eds.). (2008). Escrituras de la modernidad. Los jesuitas entre cultura retorica y cultura cientifica. Ciudad de Mexico, DF: Universidad Iberoamericana-Ehess.

Colombo, E., \& Massimi, M. (2014). Gesuiti candidati alle missioni tra Antica e Nuova Compagnia. Il Sole 24 Ore (Milano), viaggio.

De Sanctis, S. (1906). Atti del Quinto Congresso Internazionale di Psicologia tenuto in Roma dal 26 al 30 aprile 1905 sotto la presidenza di Giuseppe Sergi. Roma: Forzani Tipografia del Senato.

De Sarlo, F. (1905). Lo spiritualismo al Congresso di Psicologia. Studi Religiosi. Rivista Critca e Storica Pormotrice della Cultura Religiosa in Italia, 5, 257-269.

Dilthey, W. (1948). Introducción a las ciencias del espiritu. Buenos Aires: Espasa-Calpe. (Original publicado em 1883)

Freitas, S. A. (2010). O projeto de uma psicologia cientifica em W. Wundt. Juiz de Fora, MG: Editrice Università Federale.

Frielingsdorf, K. (2001). J. Fröbes. In C. E. O'Neil \& J. M. Dominguez, Diccionario Histórico de la Compañia de Jesús (Vol. II, p. 1534). Roma: Institutum Historicum S.I.

Fröbes, J. (1911). Psychologia Sensitiva [Manuscrito]. Archivum Romanum Societatis Iesu (ARSI, Segnatura: OPP. NN. 1028). Valkenburg, Holland.

Fröbes, J. (1917-1920). Lehrbuch der experimentellen Psychologie (Vols. 1-2). Freiburg, Germany: Herder.

Fröbes, J. (1927). Psychologia speculativa in usum scholarum. Freiburg, Germany: Herder.

Fröbes, J. (1937). Compendium Psychologiae Experimentalis. Roma: Università Gregoriana. 
Fröbes, J. (1961). Compendio de Psicologia Experimental (J. A. Menchaca, Trad.). Madri: Razón y Fe. (Original publicado em 1915)

Galton, F. (1869). Hereditary Genius. London: Macmillan.

Galton, F (1883). Inquiries into Human Faculty and Its Development. London: J. M. Dent \& Company.

Galton, F. (1889). Natural Inheritance. London: Macmillan.

Giard, L. (1995). Les jésuites á la Renaissance. Système éducatif et production du savoir. Paris: Presses Universitaires de France.

Gibert, P. (2006). Universitas Nostra Gregoriana. La Pontificia Università Gregoriana ieri e oggi. Roma: Pontifícia Universidade Gregoriana.

Grutt, C. (1920). De studio Psychologiae experimentalis et de eius habitudine ad Psychologiam rationalem. Archivum Romanum Societatis Iesu (ARSI, n. 32 de 1920 da Pasta Província alemã). Roma.

Guimerá, V. (1921). Informacion de P. Vicente Guimerá. Archivum Romanum Societatis Iesu (ARSI, Algunos apuntes sobre el estudio de ciencias em la Provincia de Aragon 1920-21, Roma, 7 dez. 1921.) Roma.

Jurado, M. R. (1997). Il discernimento spirituale. Cinisello Balsamo, Itália: San Paulo.

Lindworsky, J. (1919). Der wille, seine erscheinung und seine beherrschung, nach den ergebnissen der experimentellen forschung. Leipzig, Grmany: J.A. Bart.

Lindworsky, J. (1922).Willensshule. Padherborns, Germany: Schöning.

Lindworsky, J. (1932). Theoretical Psychology. London: B. Herder Book.

Lindworsky, J. (1939). Manuale di Psicologia sperimentale (E. Galli, Trans.). Milão, Itália: Gatti. (Original publicado em 1921)

Lindworsky, J. (1946). Psicologia de la ascetica (G. Del Valle, Trans.). Buenos Aires: Excelsa. (Original publicado em 1935)

Loeb, J (1890). Der Heliotropismus der Thiere und seine Uebereinstimmung mit dem heliotropismus der Pflanzen. Würzburgo, Germany: Verlag von Georg Hertz.

Loyola, I. (2002). Exercícios Espirituais. São Paulo, SP: Edições Loyola.
Macsey, C. (1919). Responsa ad quaesita posita in consultatione de studiis universitate Gregoriana. Archivum Romanum Societatis Iesu (ARSI, Studia 41020 Doc. 1911-19). Roma.

Maher, M. S. I. (1902). Psychology. Longan, UT: Green. (Original publicado em 1890)

Marcellos, C. F. (2012). Objeto e método na Psicologia de Wilhelm Wundt e Edward Titchener: Um estudo comparativo (Dissertação de mestrado, Universidade Federal de Juiz de Fora, MG, Brasil).

Massimi, M. (1990). História da Psicologia brasileira. Da época colonial até 1934. São Paulo, SP: Editora Pedagógica Universitária.

Massimi, M. (2004). História da Psicologia no Brasil do século $X X$. São Paulo, SP: Editora Pedagógica Universitária.

Massimi, M. (2010). A pessoa e o seu conhecimento: Algumas etapas significativas de um percurso conceitual. Memorandum, 18, 1026. Recuperado em http://www.fafich.ufmg. br/ memorandum/a18

Massimi, M. (2012). Imaginação e imagens: Conceitos e práticas em tradições culturais da modernidade ocidental e do Brasil colonial. Memorandum, 23, 158-184. Recuperado em http://www. fafich.ufmg.br/memorandum/a23/massimi06

Massimi, M. (2016). Saberes psicológicos no Brasil. Curitiba, PR: Juruá.

Massimi, M., \& Freitas, G. R. (2007). Acomodação retórica e adaptação psicológica na pregação popular dos jesuitas na Terra de Santa Cruz. Mnemosine, 3(1), 111-135.

Mercier, D. F.F. J. (1920). Psychologie. Louvain, Belgium: Institut Supérieur de Philosophie.

Michotte, A. (1962). The perception of causality. Andover, MA: Methuen.

Misiak, H., \& Staudt, V. (1954). Joseph Fröbes. Catholics in psychology: A historical survey. (pp. 84-97). New York: McGraw-Hill Book. doi:http://dx.doi.org/10.1037/11143-006.

Monaco, N. (1919). Risposte ai due quisiti proposti dal P. Rettore a nome del MRP Generale riguardo al modo d'istituire un corso superiore di teologia e filosofia all'Universitá Gregoriana. Archivum Romanum Societatis Iesu (ARSI, Studia 41020 Doc. 1911-19, Roma 16 de maio de 1919). Roma. 
Murchison, C. A. (Ed.). (1936). History of Psychology in Autobiography: Vol. 3 (pp. 121-147). Worcester, MA: Clark University Press.

OCLC Online Computer Library Center. (2010). OCLC WorldCats Identities: Lindworsky, Johannes 1875-1939. Retrieved from http://www. worldcat.org/identities/lccn-n2003-32612/

Pacheco, P. R. A. (2014a). O segundo livro do tratado De Arte Voluntatis de Juan Eusebio Nieremberg (1595-1658). IHS. Antiguos Jesuitas en Iberoamérica, 2(1), 121-194.

Pacheco, P. R. A. (2014b). O terceiro livro do tratado De Arte Voluntatis de Juan Eusébio Nieremberg (1595-1658). IHS. Antiguos Jesuitas en Iberoamérica, 2(2), 150-221.

Porta, M. A. G. (2010). Husserl: fenomenologia, psicologismo, psicologia. São Paulo, SP: Loyola.

Romano, A. (1999). La contre-réforme mathématique. Constitution et diffusion d'un culture mathématique jésuite à la Renaissance (15401640) (Coll. Bibliothèque des Écoles françaises d'Athènes et de Rome, 306). Roma: École Française de Rome

Romano, A. (2012). Jésuites et science moderne. Les voies européennes et non-européennes d'un engendrement conflictuel. In V. Jullien, E. Nicolaidis, \& M. Blay (Eds.), Europe et sciences modernes. Histoire d'un engendrement mutuel (pp. 273-296). New York: Peter Lang.

Rozestraten, R. J. A. (2004). As tentativas dos cognitivistas pioneiros. Estudos de Psicologia (Natal), 9(1), 5-15. doi:http://dx.doi.org/10.1590/ S1413-294X2004000100002

Spranger, E. (1928). Types of men: The psychology and ethics of personality (T. Pigors, Trans.). Halle, Germany: Max Niemeyer.
Stein, E, (1992). Beiträge zur philosophischen Begründung der Psychologie und der Geisteswissenschaften. In M. Niemeyer (Ed.), Jahrbuch für Philosophie und phänomenologische Forschung (Vol. 5). Halle, Germany. (Original publicado em 1922)

Thorndike, E. L. (1904). Introduction to the Theory of Mental and Social Measurements. New York: The Sciences Press.

Thorndike, E. L. (1905). The Elements of Psychology. New York: Seiler.

Thorndike, E. L. (1911). Animal Intelligence. New York: The Macmillan Company.

Titchener, E. B. (1899). An Outline of Psychology ( $3^{\text {rd }}$ ed.). New York: The Macmillan.

Titchener, E. B. (1908). Elementary Psychology of Feeling and Attention. New York: The Macmillan.

Vidal, F. (2006). Les Sciences de l'âme XVI-XVIII siècle. Paris: Champion.

Wundt, W. (1874). Grundzuge der physiologischen Psychologie. Leipzig, Germany: Engelmann.

Young, A. W. (1942). A study of the dominance of six basic motives in personality as set forth by Eduard Spranger in his book, "Types of Men". ETD Collection for AUC Robert W. Woodruff Library (Paper 404).

(C) $\mathrm{O}(\mathrm{s})$ autor(es), 2018. Acesso aberto. Este artigo está distribuído nos termos da Licença Internacional Creative Commons Atribuição 4.0 (http://creativecommons.org/licenses/by/4.0/), que permite o uso, distribuição e reprodução sem restrições em qualquer meio, desde que você dê crédito apropriado ao(s) autor(es) original(ais) e à fonte, fornecer um link para a licença Creative Commons e indicar se as alterações foram feitas. 